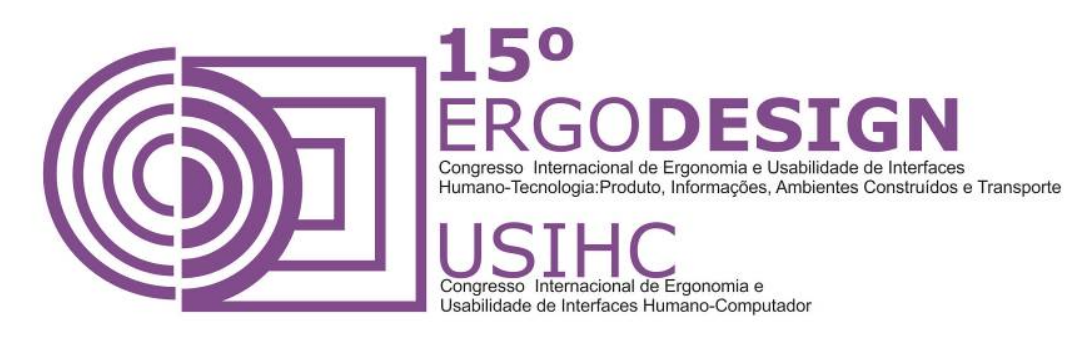

\title{
ACESSIBILIDADE NO AMBIENTE RESIDENCIAL: UM ESTUDO DE CASO EM UM CONJUNTO HABITACIONAL PARA POPULAÇÃO DE MÉDIA E BAIXA RENDAS EM JUIZ DE FORA
}

\author{
SODRÉ, Enaile Sousa Rodrigues (1) \\ RAPOSO, Myrtes (2); \\ BRAIDA, Frederico (3);
}

(1) Universidade de Juiz de Fora, Faculdade de Arquitetura e Urbanismo. Especialista em Arquitetura de Interiores (UFJF).

(2) Universidade Federal de Juiz de Fora, Inst. de Artes e Design. Mestre em Design (PUC-Rio). e-mail:myrtes.raposo@ufjf.edu.br

(3) Universidade de Juiz de Fora, Faculdade de Arquitetura e Urbanismo, Departamento de Projeto, Representação e Tecnologia. Mestre, Doutor e Pós-Doutor em Design (PUC-Rio).

e-mail: frederico.braida@ufjf.edu.br

\begin{abstract}
RESUMO
Este trabalho é fruto de uma pesquisa que teve por objetivo a análise da acessibilidade para usuários de cadeiras de rodas em uma unidade residencial de um conjunto habitacional horizontal projetado para população de média e baixa rendas do município de Juiz de Fora/ MG. Observou-se as possibilidades e limitações do espaço construído, aplicou-se o método do passeio acompanhado (desenvolvido por Dischinger) e, sob a ótica da Ergonomia do ambiente construído, confrontou-se os dados obtidos com critérios para elaboração de projetos para pessoas com deficiência, mais especificamente, para cadeirantes.
\end{abstract}

\begin{abstract}
This study is the result of a research aimed at the analysis of the accessibility available for people in wheelchairs. It was carried out at a residential unit in a horizontal housing complex whose inhabitants belong to the medium and low classes in the city of Juiz de Fora/MG. The possibilities and limitations of the building area were observed, the accompanied walks methodology (developed by Dischinger) was applied and, according to the Ergonomics of the building area, the findings were contrasted to the criteria of design for the disabled people, specifically the ones in wheelchairs.
\end{abstract}

\section{INTRODUÇÃO}

Ao projetar um imóvel, arquitetos e profissionais da área procuram aliar o conhecimento técnico às necessidades dos usuários, a fim de obter informações que irão auxiliá-los na elaboração 


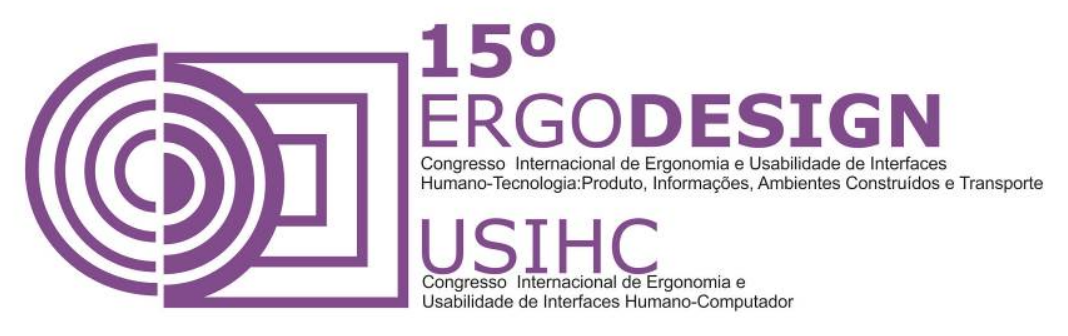

dos ambientes do futuro imóvel. No caso de um edifício residencial ou de um conjunto habitacional padronizado, em especial nos projetos para população de média e baixa renda, isso não compõe a realidade, e os usuários ficam sujeitos aos modelos impostos pelo mercado.

A questão é que a maioria dos modelos de imóveis, economicamente viáveis para população de média e baixa renda, muitas vezes não contemplam os requisitos mínimos estabelecidos nas normas técnicas, desconsiderando aspectos que envolvem a acessibilidade. Tais imóveis apresentam, por exemplo, ambientes muito reduzidos e sistemas construtivos que impossibilitam a ampliação ou a adaptação dos ambientes às necessidades dos usuários.

Nesta direção, a pesquisa se desenvolveu a partir de um estudo de caso em uma residência de um conjunto habitacional horizontal para população de média e baixa rendas, localizado na região Oeste de Juiz de Fora, e teve como objetivo analisar as condições de acessibilidade para usuários de cadeiras de rodas nesse ambiente residencial, a partir de uma vivência do método do Passeio Acompanhado - método investigativo desenvolvido por Dischinger (2000). Para tanto, se fez necessário verificar as possibilidades e limitações dentro do espaço, observar os aspectos positivos e negativos, bem como conhecer os critérios para elaboração de projetos para pessoas com deficiência, mais especificamente, para cadeirantes.

\section{DEFINIÇÕES E PRECEITOS}

A seguir, serão apresentadas definições - de forma sucinta - de conceitos que serviram como pilares para argumentação teórica, permitindo, assim, que fosse estabelecido um diálogo entre teoria e espaço analisado.

\subsection{A Pessoa com Deficiência}

Conforme a Constituição Federal (1988), toda pessoa, incluindo aquelas que apresentam deficiências, têm direito ao acesso à educação, à saúde, ao lazer, ao esporte e ao trabalho. As pessoas devem ser percebidas com igualdade, implicando assim no reconhecimento e atendimento de suas necessidades específicas. Tanto espaços públicos quanto privados devem ser projetados respeitando a diversidade humana, suas dificuldades e limitações, e devem propor soluções que sejam eficientes e que garantam a mobilidade de todos.

De fato, em algum momento de nossa vida poderemos ter mobilidade reduzida, temporária ou permanente. Pessoas pequenas ou muito grandes, as grávidas, as pessoas empurrando um carrinho de bebê ou com uma criança no colo, outras que quebram um braço ou uma perna, os obesos, ou ainda quando envelhecemos. Estamos sujeitos a esses e outros fatores que podem vir a alterar nosso modo de estar e agir, refletindo na nossa capacidade de interação com o mundo ao nosso redor.

\subsection{Acessibilidade}

Acessibilidade significa garantir espaços que apresentem condições de acesso a todas as pessoas, e a inclusão social das pessoas com deficiência deve ser um dos objetivos nas 


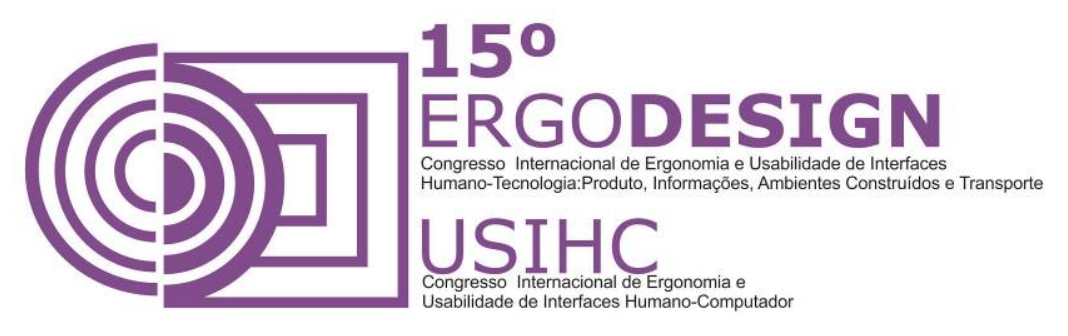

sociedades que defendem os valores da solidariedade e da integração, além do respeito pelas diferenças pessoais (BRASIL, 2007).

Visando estabelecer e direcionar as referências mínimas para a execução de projetos arquitetônicos e urbanísticos, assim como, instituir parâmetros para pessoas com deficiência ou dificuldade de locomoção, em 1985, a Associação Brasileira de Normas Técnicas (ABNT) criou a NBR 9050: Acessibilidade a edificações, mobiliário, espaços e equipamentos urbanos, revisada em 2004 e ainda em vigor regulamentando os parâmetros técnicos de acessibilidade no país. Mesmo com parâmetros estipulados na forma de lei, o cumprimento da NBR 9050, só se tornou obrigatório e passível de fiscalização quando, em 2005, o Ministério das Cidades lançou o Programa Brasil Acessível, com o intuito de estimular e apoiar os governos municipais e estaduais a assegurarem acessibilidade para pessoas com restrição de mobilidade e deficiência aos sistemas de transportes, equipamentos urbanos e a circulação em áreas públicas (CLEMENTE, 2012).

A legislação de acessibilidade no Brasil refere-se somente à aplicação da NBR 9050, restringindo a espaços públicos de uso comum, gerando, portanto, legislações municipais ou estaduais específicas que contemplem esses espaços. Em Juiz de Fora/MG — local do objeto da pesquisa - vigora a Lei 10.410 de 20 de março 2003. Esta lei estabelece normas gerais e critérios básicos para a promoção da acessibilidade das pessoas com deficiência ou com mobilidade reduzida, mediante a supressão de barreiras e de obstáculos nas vias públicas e espaços de uso público, no mobiliário urbano, na construção e na reforma de edifícios e nos meios de transportes e de comunicação.

\subsection{Ergonomia e Desenho Universal}

A Ergonomia, segundo a Associação Brasileira de Ergonomia (ABERGO), é definida como uma disciplina científica relacionada ao entendimento das interações entre os seres humanos e outros elementos ou sistemas, e à aplicação de teorias, princípios, dados e métodos a projetos a fim de otimizar o bem estar humano e o desempenho global do sistema (ABERGO, 2010).

No âmbito das preocupações da ergonomia, surgem os princípios do desenho universal em decorrência de reivindicações de dois segmentos sociais. Um segmento composto por pessoas com deficiência que não sentiam suas necessidades contempladas nos espaços projetados e o outro composto por arquitetos, engenheiros, urbanistas e designers que desejavam maior democratização do uso dos espaços e tinham uma visão mais abrangente da atividade projetual (SÃO PAULO, 2010).

A essência do Desenho Universal é certificar que todos, sejam ou não pessoas com deficiência, possam praticar suas ações cotidianas e utilizar o espaço de modo autônomo e seguro. A eficácia da interação do ser humano com o ambiente construído depende de sua própria capacidade, mas é dever do profissional da área arquitetônica e urbanística ter preocupação em criar espaços de uso democrático para diferentes perfis de usuários. (ALMEIDA; BARTHOLOMEI, 2011). 


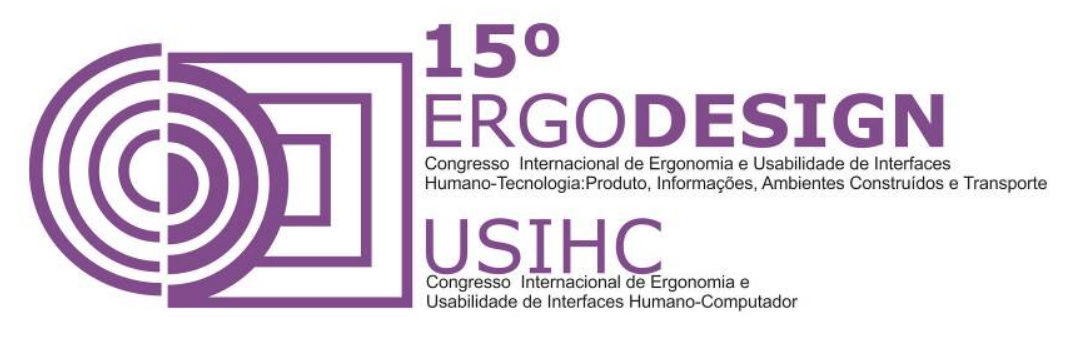

Com o intuito de sistematizar os conceitos de desenho universal, um grupo do centro de pesquisa Center for Universal Design, da Escola de Design da Universidade da Carolina do Norte desenvolveu sete princípios do desenho universal. Os princípios podem ser assim descritos: Princípio 1 - Uso correto ou uso equitativo; Princípio 2 - Uso flexível; Princípio 3 Uso simples e intuitivo; Princípio 4 - Informação perceptível; Princípio 5 - Tolerância ao erro (segurança); Princípio 6 - Esforço físico mínimo; e Princípio 7 - Dimensionamento de espaços para acesso e uso abrangente.

De acordo com a Cartilha do Desenho Universal: Habitação de Interesse Social (SÃO PAULO, 2010), a diferença entre uma habitação com Desenho Universal e uma habitação adaptada a pessoa com deficiência está na concepção do projeto. Uma habitação adaptada é voltada unicamente para pessoas com deficiência, seguindo uma série de requisitos específicos, estipulados pela NBR 9050. Por outro lado, uma habitação com Desenho Universal permite adaptações e pode ser utilizada por todas as pessoas, inclusive indivíduos com deficiência e mobilidade reduzida.

Ainda segundo a Cartilha, a aplicação do Desenho Universal em moradias para população de baixa renda evita a segregação dessa população no acesso a esse tipo de imóvel. Os resultados dos estudos nos projetos de habitação popular apresentados na cartilha apontam que os impactos na aplicação das novas diretrizes, tanto no âmbito das soluções técnicas quanto no aumento de áreas e de custos não se apresentaram muito expressivos. Variaram de $4,6 \%$ de incremento para apartamentos de três dormitórios, até no máximo, 14\% nas casas de dois dormitórios.

\section{METODOLOGIA}

A pesquisa aqui relatada se desenvolveu a partir da realização de um estudo de caso em uma residência de um conjunto habitacional horizontal para população de média e baixa rendas, no município de Juiz de Fora. Com o intuito de avaliar as condições de acessibilidade nesse ambiente residencial, foram realizadas pesquisas bibliográficas, visitas exploratórias e aplicação do Método do Passeio Acompanhado a partir de uma vivência.

\subsection{O local da Pesquisa}

O local escolhido para pesquisa foi uma residência em um conjunto habitacional horizontal. O conjunto foi selecionado por apresentar grande parte de suas ruas planas e por todas as unidades terem acesso no nível térreo, diferenciando-se dos conjuntos residenciais verticais que, em sua maioria, já apresentam problemas relacionados à acessibilidade nas áreas externas das unidades. Outro fator que colaborou para escolha deste condomínio foi o fato de estar localizado em uma região em expansão na cidade, com disponibilidade de infraestrutura e facilidade de deslocamento devido à proximidade com o centro e vias de acesso. 


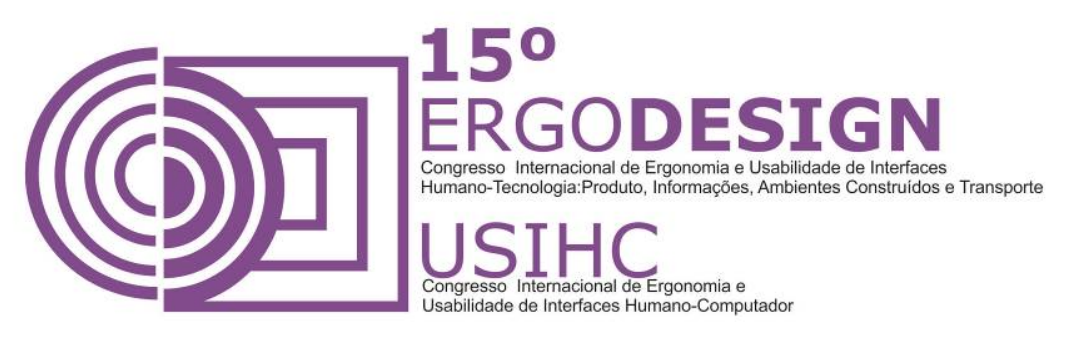

\subsection{Pesquisa Bibliográfica}

A pesquisa bibliográfica ocorreu por meio de acesso a livros, sites, artigos, periódicos, dissertações, leis, decretos, normas técnicas e documentos sobre os principais assuntos a respeito da pesquisa como: acessibilidade, desenho universal e ergonomia. A pesquisa bibliográfica transcorreu desde o início da pesquisa até sua conclusão.

\subsection{Visitas Exploratórias}

Adotou-se esse método com o intuito de observar e registrar o conjunto habitacional e a residência escolhida para a análise. Nesta fase da pesquisa foram programadas visitas gerais ao conjunto habitacional e visitas a casas de dois e de três dormitórios. Além disso, houve conversas com a síndica do condomínio, com moradores e com representantes da construtora. O registro do espaço foi realizado através de fotografias e medições técnicas, gerando dados de grande valor para caracterização da área de estudo e para o desenvolvimento da análise técnica.

\subsection{Método do Passeio Acompanhado (Vivência)}

O método do Passeio Acompanhado consiste em uma visita supervisionada no local de estudo, na companhia de um convidado a vivenciar o espaço. O pesquisador deve acompanhar 0 entrevistado, mas não conduzi-lo ou ajudá-lo. Os percursos devem possuir um ponto de partida e objetivos a alcançar. No decorrer do passeio, o interlocutor deve fazer anotações sobre as impressões do entrevistado, transcrevendo ou gravando falas importantes e fotografando situações relevantes. Os eventos significativos são fotografados e localizados em mapas sintéticos dos percursos (DISCHINGER, 2000 apud BINS ELY; ANDRADE, 2012). Nesta pesquisa, o método do passeio acompanhado foi aplicado a partir de uma vivência, pois o convidado simulou ser um cadeirante. O voluntário foi um homem de 32 anos, com peso de $80 \mathrm{Kg}$ e boas condições físicas. A cadeira adotada foi um modelo simples, para pessoas com até $100 \mathrm{Kg}$. Durante a realização dos trajetos o voluntário apontou as possibilidades e as limitações referentes ao deslocamento e a realização de tarefas dentro do espaço residencial.

\subsection{Avaliação Ergonômica (acessibilidade no espaço construído)}

A avaliação da acessibilidade no ambiente residencial considerou a legislação, as normas técnicas e as diretrizes que se aplicam aos ambientes habitacionais, apresentadas na Cartilha de Desenho Universal: Habitação de Interesse Social (SÃO PAULO, 2010). A análise foi realizada em uma residência de dois dormitórios, e os resultados foram organizados em tabelas separadas por tipo de ambiente, com textos, desenhos e fotos, sendo descritos na sequência seus aspectos positivos e negativos. 


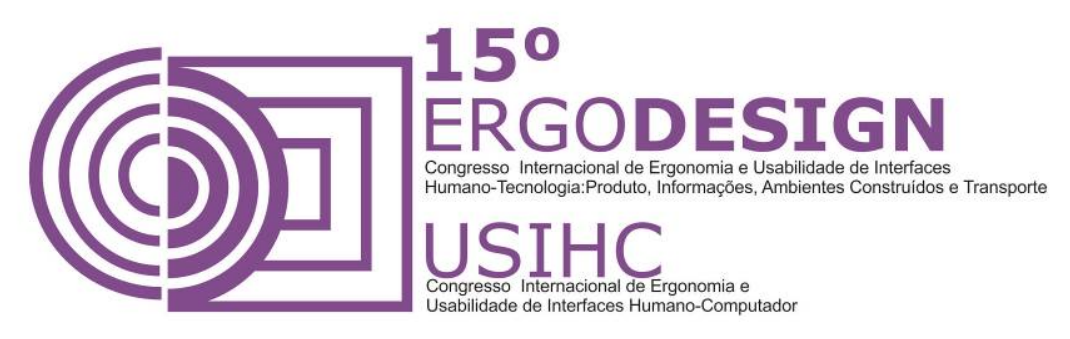

\section{ESTUDO DE CASO}

\subsection{Caracterização da Área}

O objeto de estudo analisado trata-se de uma residência de dois quartos, localizada em um conjunto habitacional horizontal para população de média e baixa renda, na Região Oeste de Juiz de Fora. O Condomínio é composto por aproximadamente 1.200 residências (figuras 1 e 2), apresentando tipologias de dois ou três quartos, com áreas de $44 \mathrm{~m}^{2}$ e $50 \mathrm{~m}^{2}$, respectivamente, e garagens individualizadas. O condomínio está cercado por muros e apresenta boa infraestrutura, com portaria monitoramento 24h, e diversos equipamentos coletivos, como quadras esportivas, praça de jogos quiosque com churrasqueira, playground entre outros.
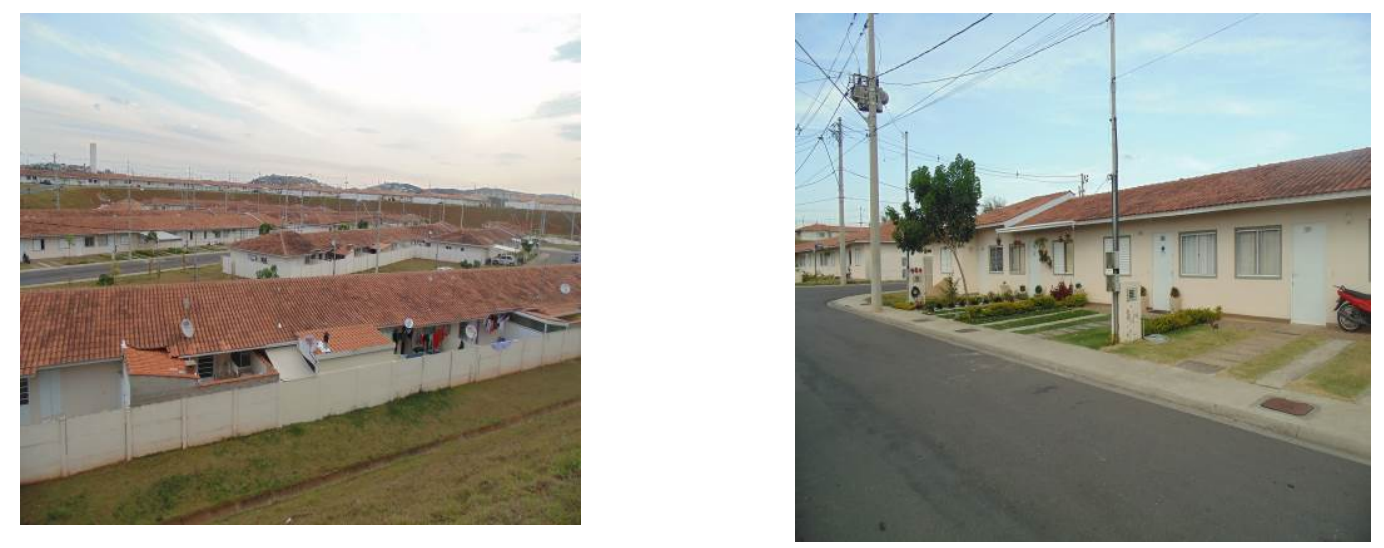

Figuras 1 e 2: Vista Geral do Condomínio e fachada de uma das residências. Fonte: dos autores, 2014.

O sistema construtivo aplicado nas unidades do condomínio foi o de paredes de concreto moldadas in loco, sistema que restringe a possibilidade de alteração dos ambientes por parte dos moradores; ou seja, há restrições ao reformar, mudar ou ampliar espaços internos em virtude de comprometer a estrutura da própria casa ou da unidade vizinha. A construtora disponibiliza modelos de projetos que contemplam modificações nas áreas externas das unidades, caso os moradores queiram realizar a cobertura da garagem ou da área de serviço. No entanto, não há projetos que considerem modificações internas, que priorizem a acessibilidade ou outra situação, ficando o morador responsável em contratar um engenheiro ou arquiteto para realizar o projeto e se responsabilizar por possíveis danos na estrutura do conjunto. Esses projetos são submetidos à análise da comissão de obras do condomínio, composta por moradores, engenheiros e arquitetos da construtora.

\subsection{Relatório do Método do Passeio Acompanhado (Vivência)}

O passeio acompanhado durou aproximadamente $40 \mathrm{~min}$. O percurso iniciou-se na calçada, que se apresenta um pouco irregular, no entanto não atrapalhou a locomoção. O voluntário 


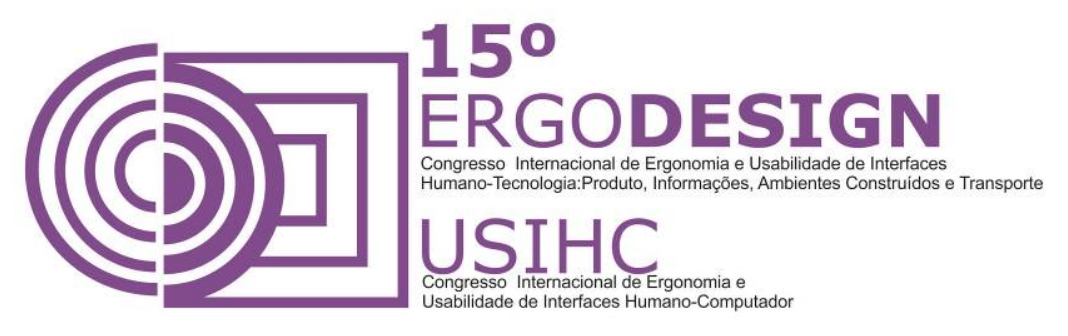

conseguiu seguir pelo acesso ao lado da garagem e chegar à porta principal sem a ajuda de terceiros. Depois disso, passou pela sala de estarl jantar, sem esbarrar nos móveis, teve espaço suficiente para manobrar a cadeira, no entanto não houve área para aproximação à janela. Seguindo até a cozinha foi possível se aproximar da pia, do fogão e do móvel para guarda de utensílios, porém a pia estava com altura superior a ideal, que não deve ultrapassar $85 \mathrm{~cm}$, e o armário sob a bancada dificultou o acesso a torneira. Foi possível se aproximar da janela da cozinha, porém a altura em que ela foi instalada impossibilitou seu manuseio.

O voluntário prosseguiu para a área de serviço, onde se constatou facilidade no acesso e na aproximação tanto da máquina de lavar quanto do tanque. Como o espaço foi coberto e todo piso nivelado, houve área suficiente para manobra da cadeira. Depois, seguiu-se para a parte da residência onde se encontram os dormitórios e o banheiro. No pequeno hall de circulação não houve espaço suficiente para manobra, impossibilitando o acesso aos dormitórios. Seria possível o acesso ao banheiro, no entanto, a porta apresenta largura inferior a $80 \mathrm{~cm}$ e seu espaço interno não possibilita área de aproximação ao lavatório, área de transferência à bacia sanitária e ao box do chuveiro, nem área de manobra para entrar e sair de frente.
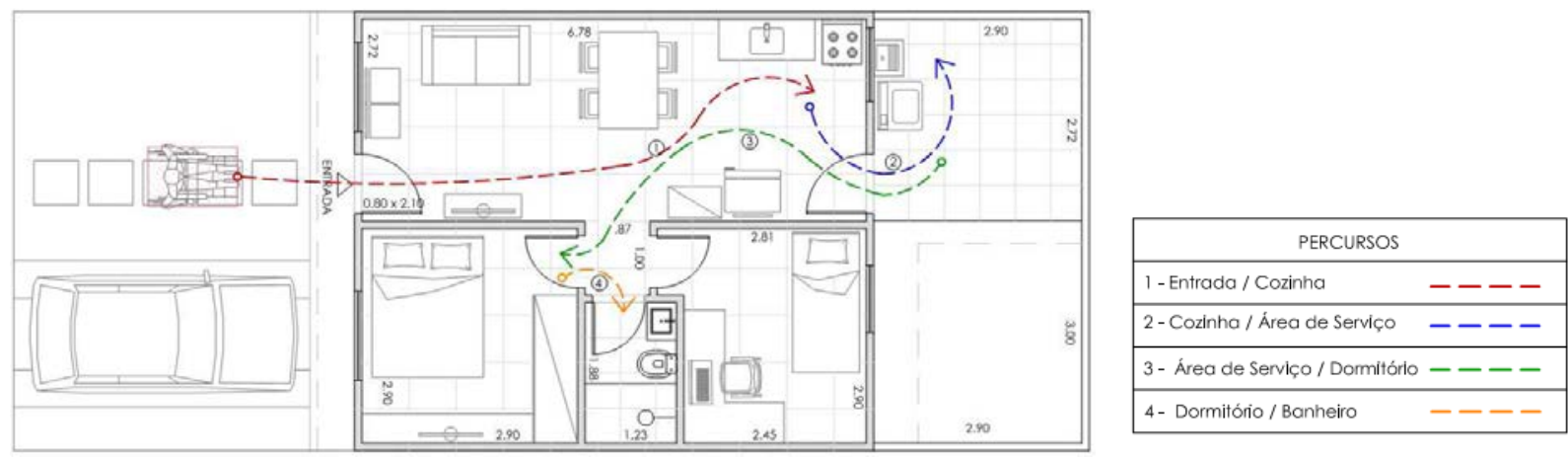

Figura 2 - Mapa dos Percursos do Passeio Acompanhado. Fonte: dos autores, 2014.

\subsection{Avaliação Técnica}

Para cada ambiente, foi estabelecido um percurso. E os dados levantados foram compilados em tabelas apresentaram registros fotográficos e layout bem como uma análise dos pontos positivos e negativos vivenciados pelo voluntário durante o trajeto. Exemplo: 


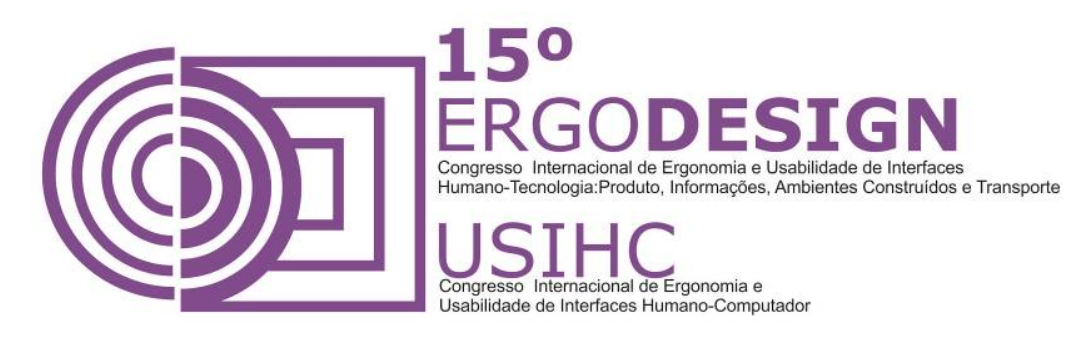

Tabela 1 - Tabela de registro dos dados levantados.

\section{AMBIENTE: SALA DE ESTAR/JANTAR}

TAREFA: Realizar o percurso da porta de entrada até a cozinha.
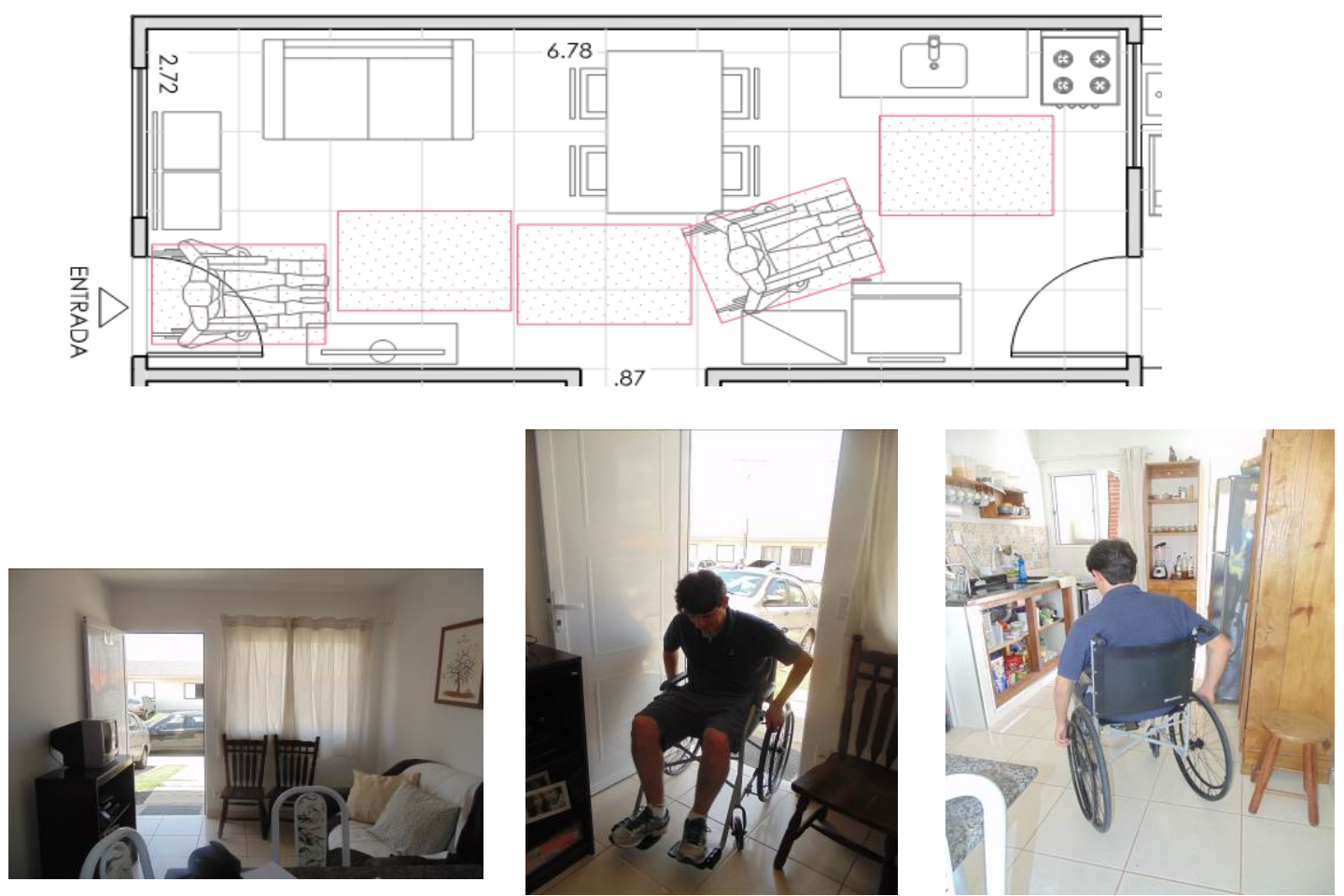

ASPECTOS POSITIVOS: - Porta de entrada com largura suficiente;

- Facilidade em se deslocar dentro do ambiente;

- Distância adequada entre os móveis;

- Área de manobra suficiente para entrar e sair de frente;

ASPECTOS NEGATIVOS:- Falta de área de aproximação à janela.

Fonte: dos autores, 2014.

\subsubsection{Síntese dos Resultados}

Os resultados obtidos com a análise da residência indicam que:

Como aspectos positivos pode-se considerar, inicialmente, que tipologias horizontais apresentam, potencialmente, melhor acessibilidade física se comparadas às tipologias em 


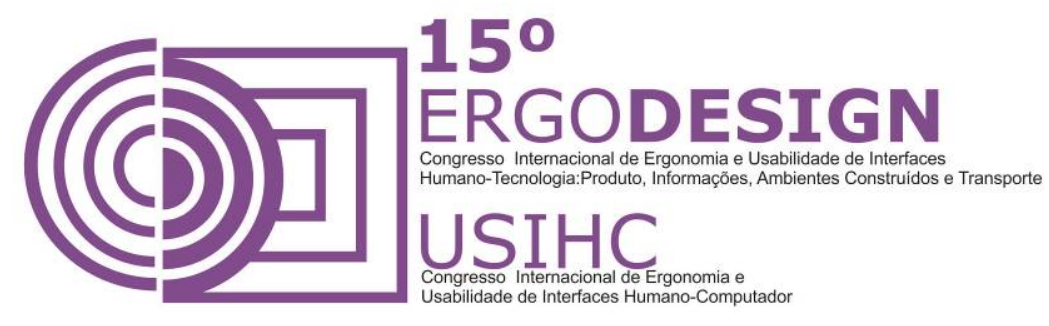

altura, e nesse aspecto todas as unidades são térreas e a grande maioria apresenta acesso plano. Também foi possível notar certa possibilidade de adequação dos ambientes da sala, da cozinha e da área de serviço, visto a presença de portas com largura suficiente para passagem da cadeira de rodas, a existência de áreas de manobra e aproximação do mobiliário e equipamentos, e a possibilidade de dispor o mobiliário necessário com distância adequada entre eles.

Como aspectos negativos apontam-se alturas inadequadas de instalação de janelas e equipamentos, assim como problemas no banheiro e nos dormitórios. As questões principais são o dimensionamento reduzido desses ambientes seguido pela falta de flexibilidade, proveniente do sistema construtivo aplicado. Verificou-se pela análise da planta baixa que tanto nos dormitórios, quanto no banheiro não haveria espaço suficiente para área de aproximação e/ou transferência ao mobiliário e aos equipamentos, nem tampouco área de manobra para o cadeirante entrar e sair de frente. Observa-se que a residência apresenta certa possibilidade de adequação apenas em alguns ambientes, o que não é suficiente, visto que o cadeirante precisa ter acesso e áreas suficientes de aproximação, transferência e manobra em todos os ambientes da casa.

\subsubsection{Sugestões Ergonômicas}

A partir da análise dos resultados e da revisão teórica realizada fica evidente se tratar de um projeto que priorizou o custo e o espaço em detrimento de um projeto acessível. As sugestões a seguir visam propor um ambiente mais favorável e mais adequado às necessidades dos cadeirantes. Um dos aspectos negativos citado na pesquisa foi a altura inadequada de janelas e equipamentos como torneiras e tomadas, uma vez que o voluntário não conseguiu alcançar e manusear esses dispositivos. Desta forma, a Cartilha de Desenho Universal: Habitação de Interesse Social (SÃO PAULO, 2010, p.48 e 59) define que janelas, campainhas, interruptores, entre outros itens, devem estar a uma distância de $50 \mathrm{~cm}$ na horizontal, para superfícies de trabalho, e alturas compreendidas entre $40 \mathrm{~cm}$ e $1,20 \mathrm{~m}$ a partir do piso. A área de visibilidade deve estar situada a, no máximo, $60 \mathrm{~cm}$ de altura a partir do piso, permitindo alcance visual para pessoa sentada. Quanto à altura de torneiras, a cartilha recomenda que estejam a, no máximo, $85 \mathrm{~cm}$ a partir do piso, e distantes até $50 \mathrm{~cm}$ da borda da bancada, atentando também para área de aproximação frontal, com espaço livre de $25 \mathrm{~cm}$ sob o móvel.

Foram constatados também problemas nos dormitórios e no banheiro referentes ao dimensionamento reduzido, falta de flexibilidade, falta de área de aproximação e manobra, visto que o voluntário não conseguiu sequer entrar nesses ambientes. O ideal seria que o projeto contemplasse tais modificações, sem que isso implicasse em problemas estruturais e altos custos. A NBR 9050 (ABNT, 2004, p.70,71 e 84), define a área de circulação mínima em dormitórios e sanitários, desta forma propõe-se, primeiramente, o aumento da área do hall de entrada dos quartos e do banheiro e também o aumento da abertura das portas, que passariam de $70 \mathrm{~cm}$ para $80 \mathrm{~cm}$. A segunda modificação implicaria na ampliação das dimensões desses ambientes, o quarto, por exemplo, passaria da metragem de 2,90m x 2,90m (figura 3) para $2,90 \mathrm{~m} \times 3,80 \mathrm{~m}$ (figura 4), e o banheiro passaria de 1,23m $\times 1,88$ (figura 5) para 1,95m x 2,35m 


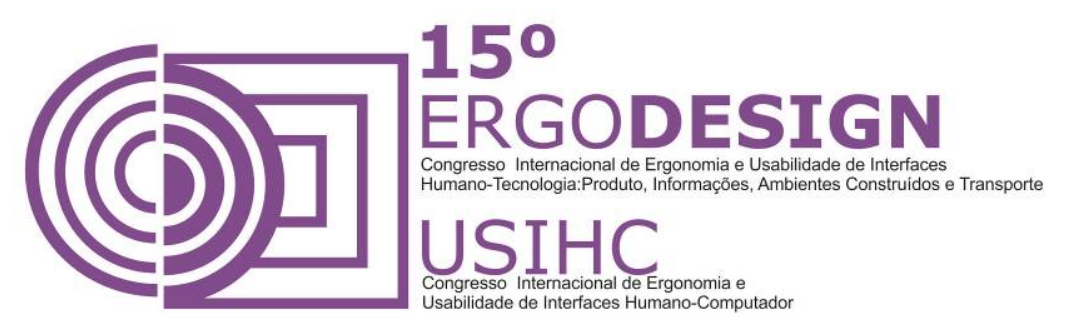

(figura 6). A terceira modificação seria a respeito do layout, pois um melhor posicionamento do mobiliário e dos equipamentos garantiria as áreas necessárias para circulação, transferência e manobra do cadeirante dentro do espaço.

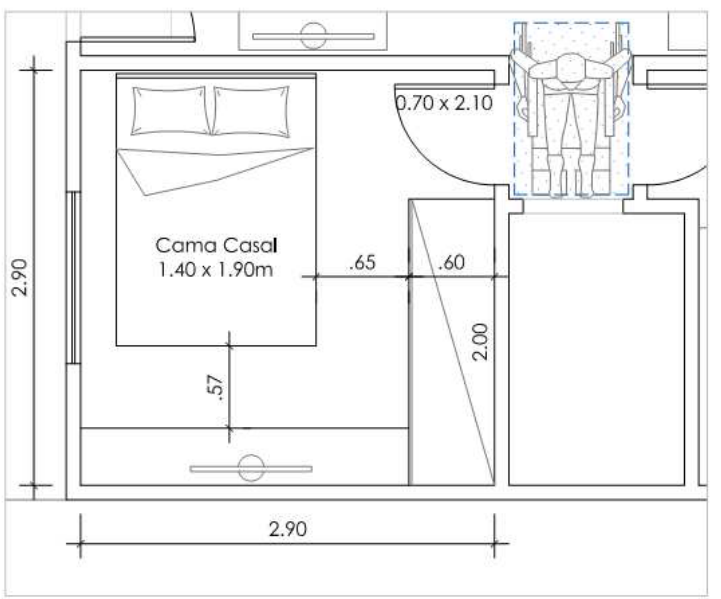

Figura 3 - Dimensões e Layout existentes no Quarto de Casal. Fonte: dos autores, 2014.

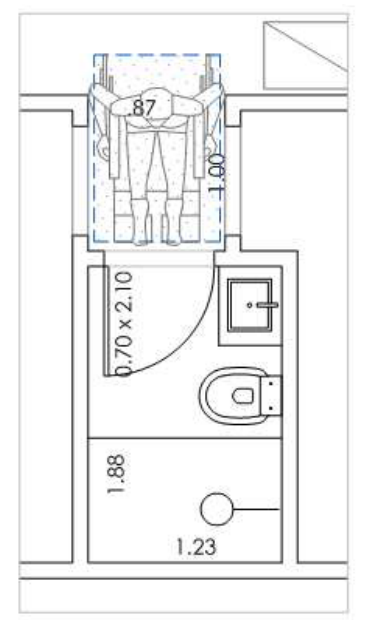

Figura 5 - Dimensões e Layout existentes no Banheiro. Fonte: dos autores, 2014.

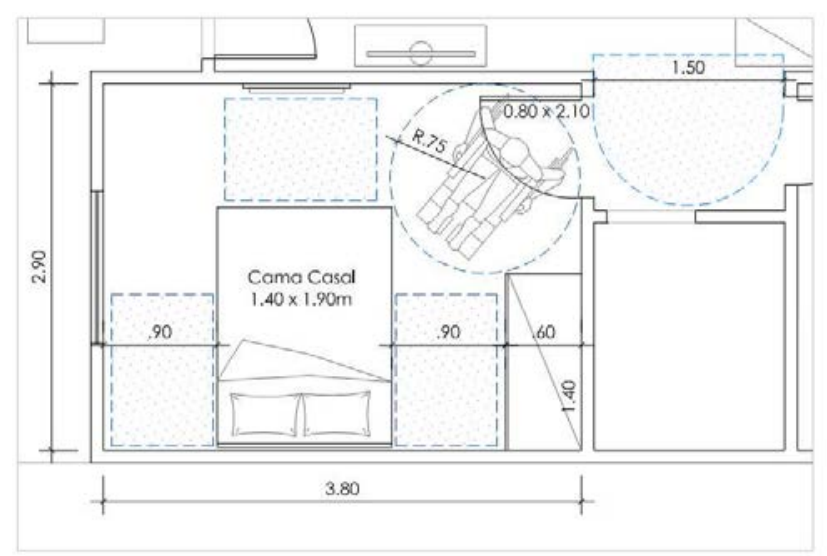

Figura 4 - Sugestões para adequação do Quarto de Casa. Fonte: dos autores, 2014.

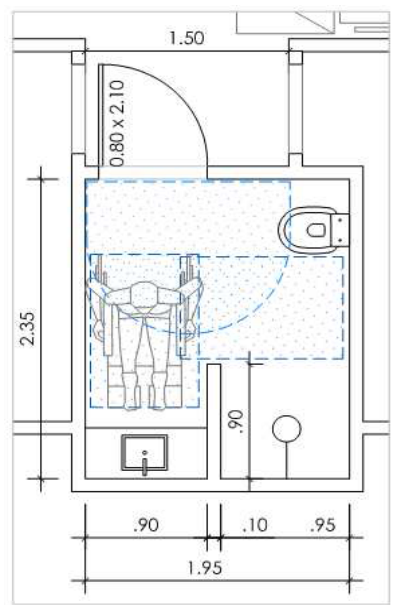

Figura 6 - Sugestões para adequação do Banheiro. Fonte: dos autores, 2014.

\section{CONSIDERAÇÕES FINAIS E DESDOBRAMENTOS}

A produção de espaços verdadeiramente acessíveis inclui algumas ações que devem ser trabalhadas de forma a assegurar funcionalidade, qualidade e conforto, em todos os espaços, especialmente nos ambientes habitacionais. Além dos conhecimentos técnicos, a 


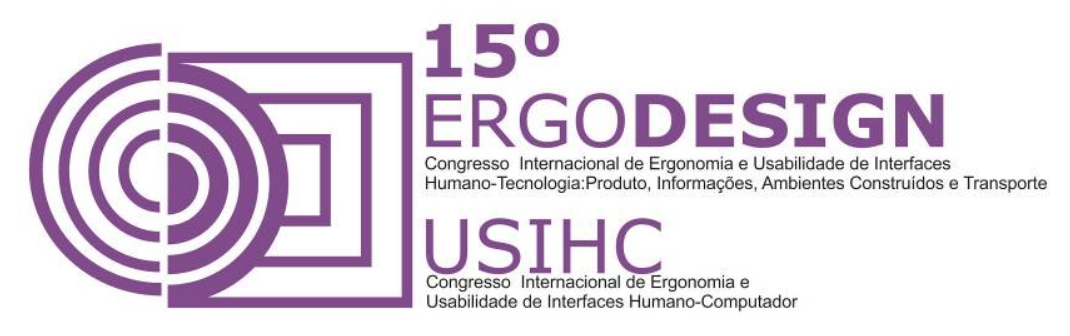

conscientização profissional e a análise crítica quanto à produção habitacional também se fazem necessárias, uma vez que é crescente o número de pessoas com algum tipo de limitação, incluindo pessoas idosas, obesas, crianças, ou que utilizam bengalas, muletas, entre outros. Os espaços devem ser "inclusivos" de maneira que cidadãos com deficiência ou mobilidade reduzida possam exercer suas atividades da mesma forma como aqueles que não apresentam essas dificuldades. A essência dos princípios do Desenho Universal está no propósito de fornecer acessibilidade integrada a todos, independente de habilidades físicas, idade, ou condições socioeconômicas. E nesse viés, arquitetos, designers de interiores e profissionais da área devem estar cientes de seu compromisso social no momento de projetar para população de média e baixa renda, criando espaços acessíveis ou passíveis de adaptações, e que sejam ao mesmo tempo economicamente viáveis para esse público.

Por fim, espera-se que a pesquisa aqui relatada contribua com os estudos do campo da acessibilidade em ambientes residenciais, estimulando os profissionais envolvidos na questão da habitação: arquitetos, engenheiros, designers de interiores e empreendedores da construção a pensarem nos espaços planejando-os com vistas à qualidade de vida.

\section{REFERÊNCIAS BIBLIOGRÁFICAS}

ALMEIDA, Paula Aparecida Santini; BARTHOLOMEI, Carolina Lotufo Bueno. Acessibilidade de "Cadeirantes" no Espaço de Ensino Público. Revista Eletrônica Tópos, Vol. 05, n.02, p. 21-46, 2011. Disponível em: <http://revista.fct.unesp.br/index.php/topos/article/view/2283/2088>. Acesso em: 11 nov. 2014.

ASSOCIAÇÃO BRASILEIRA DE ERGONOMIA (ABERGO). O que é ergonomia. Rio de Janeiro, 2010. Disponível em: <http://www.abergo.org.br/internas.php?pg=o_que_e_ergonomia>. Acesso em: 20 ago. 2014.

ASSOCIAÇÃO BRASILEIRA DE NORMAS TÉCNICAS. NBR 9050: Acessibilidade de pessoas portadoras de deficiências a edificações, espaço, mobiliário e equipamentos urbanos. Rio de Janeiro, 2004.

BINS ELY, Vera Helena Moro; ANDRADE, Isabela Fernandes. Edificações Históricas Preservadas: Intervir para torná-las acessíveis. Associação Brasileira de Ergonomia. Revista Eletrônica Ação Ergonômica, Vol. 07, n. 02, 2012. Disponível em: <http://www.abergo.org.br/revista/index.php/ae/issue/view/17>. Acesso em: 20 ago. 2014.

BRASIL. Senado Federal. Constituição Federal. Brasília, Senado Federal, 1988.

Decreto $n^{\circ}$ 5.296, de 2 de dezembro de 2004. Regulamenta as Leis n. 10.048, de 8 de Novembro de 2000 e 10.098, de 19 de Dezembro de 2000. Estabelece normas gerais e criterios básicos para a promoção da acessibilidade das pessoas com deficiencia ou mobilidade reduzida, e dá outras providências. Brasília, 2004.

Ministério do Trabalho e Emprego (MTE). A inclusão de pessoas com deficiência no mercado de trabalho. 2. ed., Brasília, MTE, Secretaria de Inspeção do Trabalho, 2007. Disponível em: <http://www.acessibilidade.org.br/cartilha_trabalho.pdf>. Acesso em: 13 nov. 2014. 


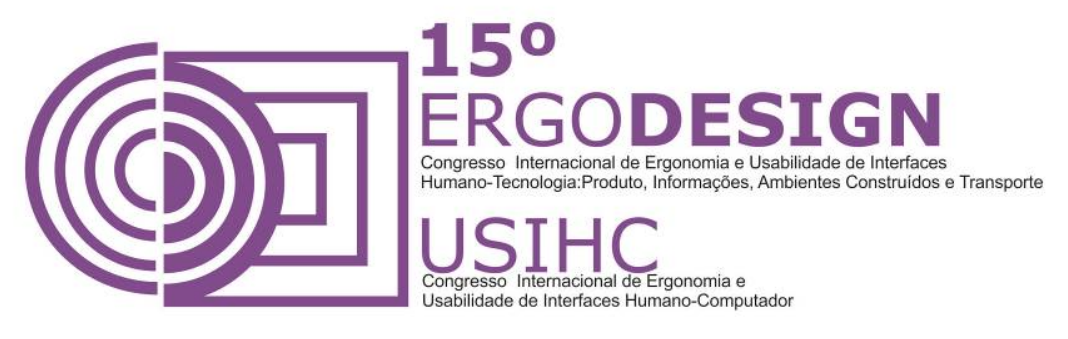

CÂMARA MUNICIPAL DE JUIZ DE FORA. Lei 10.410, de 20 de março de 2003. Juiz de Fora, 2003. Disponível em: < https://www.leismunicipais.com.br/a/mg/j/juiz-de-fora/lei-ordinaria/2003/1041/10410/leiordinaria-n-10410-2003-regulamenta-o-art-45-da-lei-organica-do-municipio-de-juiz-de-fora-estado-deminas-gerais-estabelece-normas-gerais-e-criterios-basicos-para-a-promocao-da-acessibilidade-daspessoas-portadoras-de-deficiencia-ou-com-mobilidade-reduzida-e-da-outrasprovidencias?q=acessibilidade>. Acesso em 11 nov. 2014.

CAMBIAGHI, S. Desenho Universal: métodos e técnicas para arquitetos e urbanistas. São Paulo: Editora Senac São Paulo, 2007.

CHAVES, Souza Telma. Estudo de Caso: A Cidade de Juiz de Fora MG - Sua Centralidade e Problemas Sócio-Econômicos. Revista Geomae, Juiz de Fora, Vol. 02, № Esp. 01, $2^{\circ}$ Sem/2011.

CÍRICO, Luiz Alberto; MERINO, Andréz Díaz. Por dentro do espaço habitável: Uma análise ergonômica de apartamentos e seus reflexos nos usuários. Florianópolis: Universidade Federal de Santa Catarina, 2001. 140f. Dissertação (Mestrado) - Programa de Pós Graduação em Engenharia de Produção, UFSC, Florianópolis, 2001.

CLEMENTE, Eliane de Fátima Bizinotto. Análise da evolução construtiva de acessibilidade aplicada à arquitetura residencial. Revista Eletrônica Especialize, Maio de 2012. Instituto de Pós-Graduação. Disponível em: <http//:www.ipog.edu.br/uploads>. Acesso em: 12 nov. 2014

DISCHINGER, Marta. Designing for alll senses: accessible spaces for visually impaired citizens. 2000. 260f. Thesis (Doctor of Philosophy) - Department of Space and Process School of Architecture, Chalmers University of Technology, Göteborg, Suécia, 2000.

FUNDAÇÃO JOÃO PINHEIRO. Centro de Estatística e Informações. Déficit Habitacional no Brasil $20112012 . \quad$ Belo Horizonte, 2014. Disponível em: <http://www.fjp.mg.gov.br/index.php/docman/cei/deficit-habitacional/360-nota-tecnica-deficit-habitacionalno-brasil-anos-2011-e-2012/file>. Acesso em: 12 nov. 2014.

INSTITUTO BRASILEIRO DE GEOGRAFIA E ESTATÍSTICA (IBGE). Estatísticas de Gênero: uma análise dos dados do Censo Demográfico de 2010. Disponível em: <http://biblioteca.ibge.gov.br/visualizacao/livros/liv88941.pdf>. Acesso em: 20 nov. 2014.

SÃO PAULO (Estado). Desenho universal: habitação de interesse social. São Paulo: [s.n.], 2010. Disponível em: <www.mp.sp.gov.br/portal/page/portal/Cartilhas/manual-desenho-universal.pdf.> Acesso em: 20 ago. 2014.

SOUZA, Jacqueline Emerich. O interior da habitação popular: uma análise do arranjo do mobiliário pela ótica da Ergonomia. Revista Eletrônica Especialize, Janeiro de 2013. Instituto de Pós-Graduação. Disponível em: <http//:www.ipog.edu.br/uploads>. Acesso em: 14 out. 2014

\section{AGRADECIMENTOS}

Os agradecimentos são direcionados à FAPEMIG (Fundação de Amparo a Pesquisa do Estado de Minas Gerais), pelo apoio financeiro destinado à apresentação deste trabalho. 